\title{
Numerical Investigation on Downstream Increase in Peak Discharge of Hyperconcentrated Floods in the Lower Yellow River
}

\author{
Zhijing Li1,2, Zhongwu Jin ${ }^{1,2}$ \\ ${ }^{1}$ Changjiang River Scientific Research Institute, Wuhan, China \\ ${ }^{2}$ Collaborative Innovation Center for Geo-Hazards and Eco-Environment in Three Gorges Area, Yichang, China \\ Email: Izjketty@126.com
}

Received 11 January 2016; accepted 6 April 2016; published 13 April 2016

\begin{abstract}
Hyperconcentrated floods in the Yellow River usually accompanied with some peculiar phenomena that cannot be explained by general conceptions of ordinary sediment-laden flow (e.g., downstream increase in peak discharge, instability flow, ripping up the bottom). Up to date, the mechanisms for the abnormal phenomena are not well understood. The aim of this paper is to facilitate a new insight into the abnormal downstream increase in peak discharge of hyperconcentrated floods in the lower Yellow River. Numerical model experiments have been conducted on a typical flood occurred in August 1992 in the Lower Yellow River during which the peak discharge at Huayuankou station was $1690 \mathrm{~m}^{3} / \mathrm{s}$ larger than the value at Xiaolangdi station at upstream. It is found that a fully coupled model that incorporates the contribution of bed evolution to the mass conservation of the water-sediment mixture, can reasonably well capture the characteristics of peak discharge rise and severe bed scour, while separate numerical experiment using a decoupled model, which ignores the feedback effects of bed evolution, shows no rise in the peak discharge. This leads us to comment, if only briefly, that the entrainment of sediment due to bed erosion is the main reason for causing peak discharge increase along downstream course.
\end{abstract}

\section{Keywords}

Hyperconcentrated Flood, Abnormal Phenomena, Peak Discharge Increase, Sediment Transport, Mathematical Model

\section{Introduction}

Hyperconcentrated flow is identified as a kind of complex sediment laden flow carrying a large amount of sediments with high concentration and certain fine particles, which is a typical solid and liquid two-phase flow [1]. The mechanism and hydraulic features of hyperconcentrated floods are complicated and are different from those 
of low sediment concentration floods [2] [3]. In the Yellow River and its tributaries on the Loess Plateau, hyperconcentrated flood occurs frequently during the rainy seasons [4]. Large amount of sediment load is transported during hyperconcentrated floods. Both the historical maximum concentration of $1600 \mathrm{~kg} / \mathrm{m}^{3}$ and the mean annual amount for sediment transport of 1600 million tons are the highest values worldwide [5]. The fluvial process is extremely rapid with the river morphology altered more at a faster rate by one hyperconcentrated flood than by normal flow and low sediment concentration floods over a decade. In turn, the rapid fluvial process also changes the propagation of flood waves and induces peculiar phenomena.

When flood propagates downstream, peak discharge decreases usually due to head loss or channel storing. However, this situation is altered when the duration of hyperconcentrated flood is fairly long [6]. In August 1992 ("92.8”), a hyperconcentrated flood happened in the Yellow River on the Loess Plateau. Without flow input from regions between, the peak discharge at Huayuankou station was measured as $6260 \mathrm{~m}^{3} / \mathrm{s}$ which was $1,690 \mathrm{~m}^{3} / \mathrm{s}$ larger than the value at Xiaolangdi station $\left(4570 \mathrm{~m}^{3} / \mathrm{s}\right)$ at upstream with a length of $128 \mathrm{~km}$. This phenomenon was also observed during hyperconcentrated flood occurred in August 1973 ("73.8”) and August 2004 ("04.8"). In recent decades, a lot of field investigations of the hyperconcentrated flood in the rivers on the Loess Plateau have been carried out by Chinese hydraulic engineers and sediment measurements have been done over a long time period by more than 10,000 people working at 122 hydrological stations on the river and its tributaries [7]. However, no calibrated and validated predictive sediment transport model exists today which can accurately simulate hyperconcentrated floods.

This paper has made a numerical investigation of hyperconcentrated floods, the typical flood ("92.8”) occurred in the Lower Yellow River is studied with a series of numerical experiments. A range of effective schemes that can capture shock waves and sharp fronts reasonably well is deployed for solving the model equations [8]. Computed results and theoretical analysis indicate that the entrainment of sediment due to bed erosion is the main reason for causing peak discharge increase along downstream course.

\section{Model Formulations}

\subsection{Governing Equations}

Consider 1D flow in an open channel with rectangular cross-sections of constant width. The complete governing equations for the flow, sediment transport and morphological evolution are built upon the mass and momentum conservation equations for the water-sediment mixture and the mass conservation equations respectively for sediment carried in the flow and bed material [9], which in general read

$$
\begin{gathered}
\frac{\partial h}{\partial t}+\frac{\partial h u}{\partial x}=\frac{E-D}{1-p} \\
\frac{\partial h u}{\partial t}+\frac{\partial}{\partial x}\left(h u^{2}+\frac{1}{2} g h^{2}\right)=g h\left(J-S_{0}\right)-\frac{u\left(\rho_{0}-\rho\right)(E-D)}{\rho(1-p)}-\frac{\Delta \rho g h^{2}}{2 \rho} \frac{\partial C}{\partial x} \\
\frac{\partial h C}{\partial t}+\frac{\partial h u C}{\partial x}=E-D \\
\frac{\partial z}{\partial t}=\frac{D-E}{1-p}
\end{gathered}
$$

where $t=$ time; $x=$ streamwise coordinate; $h=$ flow depth; $u=$ depth-averaged streamwise velocity; $z=$ bed elevation; $C=$ flux-averaged volumetric sediment concentration; $g=$ gravitational acceleration; $J=-\partial z / \partial x=$ bed slope; $S_{0}=$ friction slope; $p=$ bed sediment porosity; $E, D=$ sediment entrainment and deposition fluxes across the bottom boundary of flow, representing the sediment exchange between the water column and bed; $\rho=\rho_{w}(1-C)+\rho_{s} C=$ the density of water-sediment mixture; $\rho_{0}=\rho_{w} p+\rho_{s}(1-p)=$ the density of the saturated bed; $\rho_{w}, \rho_{s}=$ densities of water and sediment, respectively; and $\Delta \rho=\rho_{s}-\rho_{w}$.

\subsection{Auxiliary Relationships}

The template is used to format your paper and style the text. All margins, column widths, line spaces, and text fonts are prescribed; please do not alter them. You may note peculiarities. For example, the head margin in this 
template measures proportionately more than is customary. This measurement and others are deliberate, using specifications that anticipate your paper as one part of the entire journals, and not as an independent document. Please do not revise any of the current designations.

To close the governing equations of models for fluvial sediment transport, auxiliary relationships are required. For the friction slope, the conventional empirical relation is used, which involves the Manning roughness $n$

$$
S_{0}=n^{2} u^{2} / h^{4 / 3}
$$

Sediment exchange between the flow and bed involves two distinct mechanisms, i.e., bed sediment entrainment due to turbulence and possibly interaction between sediment particles, and also sediment deposition due to gravitational action. The determination of the entrainment and deposition fluxes continues to be one of the pivotal components of computational models for sediment transport and morphological evolution. The traditional and extensively used approach to specifying bed sediment entrainment flux is based on the premise that entrainment occurs always at the same rate as it does under equilibrium conditions. Here, the entrainment and depositions fluxes are estimated by

$$
\begin{gathered}
E=\alpha \omega C_{e}\left(1-\alpha C_{e}\right)^{m} \\
D=\alpha \omega C(1-\alpha C)^{m}
\end{gathered}
$$

where $\omega$ is the settling velocity of a single sediment particle in tranquil water, which can be calculated using for instance Zhang's formula [1], $m=4.45 R_{p}^{-0.1}$ is the exponent denoting the effects of hindered settling due to high sediment concentrations, $R_{p} \equiv \omega d / v$ is the particle Reynolds number, $d$ is the sediment diameter, and $v$ is the kinematic viscosity of water.

$C_{e}$ is the sediment transport capacity exclusively determined by local flow conditions. In general, sediment transport capacity of hyperconcentrated flow is more complicated than that of common sediment-laden flows [10]. The high sediment concentration induces an increase of the fluid viscosity and a decreasing sediment settling velocity due to hindered settling, these effects result that less energy is required to keep sediments in suspension. At the same time, the erosion rate probably decreases with the high sediment concentration flow where less water available to penetrate into the bed and erode bed sediments [11]. However, as the density of the eroding fluid increases, the density difference between the bed and the fluid decreases, the lift force required to erode sediments decreases.

Here, the well-tested and widely used semi-empirical formula of Zhang and Xie (1993), which is explicitly reformulated by [12] is employed

$$
c_{e}=\frac{1}{20 \rho_{s}} \frac{\left[u^{3} / g h \omega\right]^{1.5}}{1+\left[u^{3} / 45 g h \omega\right]^{1.15}}
$$

$\alpha$ is a coefficient denoting the difference between near-bed concentration and depth-averaged concentration of sediment. The following relationship which has a similar approach of depth integration of the Einstein sediment transport formula is introduced [2] [13] [14].

$$
\alpha=(h u) /\left[11.6 u_{*}\left(2.303 \log \left(\frac{30.2 h}{K_{s}}\right) I_{1}+I_{2}\right]\right.
$$

where $K_{s}$ is the roughness height, and

$$
\left\{\begin{array}{l}
I_{1}=0.216 \frac{(a / h)^{R_{n}-1}}{(1-a / h)^{R_{n}}} \int_{a}^{h}\left(\frac{1-y}{y}\right)^{R_{n}} d y \\
I_{2}=0.216 \frac{(a / h)^{R_{n}-1}}{(1-a / h)^{R_{n}}} \int_{a}^{h}\left(\frac{1-y}{y}\right)^{R_{n}} \ln y d y
\end{array}\right.
$$

where $a$ = reference level, $R_{n} \equiv \omega / \kappa u_{*}$ is Rouse number (i.e., suspension index), defined as the ratio of sediment settling velocity to the product of von Karman constant $\kappa$ and bed shear velocity $u_{*}$.

It is appreciated that existing formulations of sediment entrainment and deposition fluxes remain empirical and the roughness parameter is hard to establish for natural rivers, especially as it is influenced by sediment. 
Thus Equations (5) to (10) represent only one set of the viable relationships closing the governing equations of fluvial sediment transport models.

\subsection{Numerical Algorithm}

The complete governing equations are first rewritten in conservative form, and then computed following a second-order TVD scheme that is an extension of the first-order centered FORCE scheme. The SLIC approximate Riemann solver is employed in this study [8]. The present capacity and non-capacity models are essentially adapted from a coupled model for turbidity currents over erodible sediment bed, and have been compared with that based on TVD-WAF along with HLLC approximate Riemann solver.

\section{Numerical Case Study}

In August 1992 (“92.8”), a hyperconcentrated flood happened in the Yellow River on the Loess Plateau. Abnormal changes of flood peak discharge can be observed from Figure 2. The peak discharge at Huayuankou station was measured as $6260 \mathrm{~m}^{3} / \mathrm{s}$ which was $1690 \mathrm{~m}^{3} / \mathrm{s}$ larger than the value at Xiaolangdi station $\left(4570 \mathrm{~m}^{3} / \mathrm{s}\right)$ at upstream. In this study, numerical experiments have been conducted on this typical hyperconcentrated flood. Numerical cases are summarized in Table 1. Case 1 employs the fully coupled model (Equations (1) to (4)) as to simulate the abnormal increase of the peak flow rate along the downstream course. Case 2 uses a decoupled model with the right hand side (RHS) of Equation (1) ignored. The initial flow is set to be in equilibrium and capacity state of sediment transport (see Table 1), and the inlet boundary conditions are imposed by the hydrograph of flow and sediment in Xiaolangdi station (see Figure 1(a)). The average river width is set as $800 \mathrm{~m}$, and other relevant parameters are specified as: $d=0.03 \mathrm{~mm}, \rho_{w}=1000 \mathrm{~kg} / \mathrm{m}^{3}, \rho_{s}=2650 \mathrm{~kg} / \mathrm{m}^{3}, g=9.8 \mathrm{~m} / \mathrm{s}^{2}$, $p=0.4, n=0.012$.

\section{Results and Discussion}

Figure 2 illustrates the comparison between computed results from Case 1 and measured data at Huayuankou station which is $128 \mathrm{~km}$ downstream of Xiaolangdi station. From Figure 2(a) we can see that the computed discharge hydrographs indicate that during the about 7 days flooding period of " 9.28 ", the flood peak is reduced along the downstream course at the early stage, however, during late period of this flood, abnormal flood peak changes happens, peak discharge increase along downstream and discharge at downstream becomes lager than that of upstream.

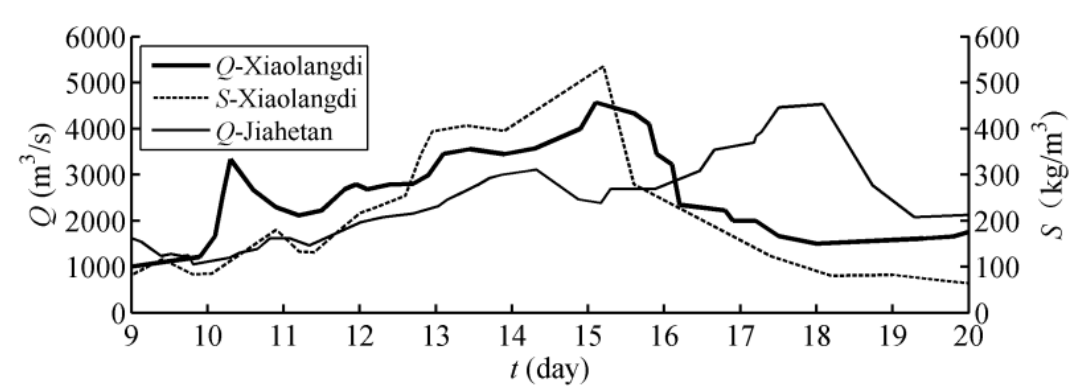

Figure 1. Measured discharge and sediment concentration used as boundary conditions.

Table 1. Summary of numerical cases.

\begin{tabular}{ccc}
\hline Case No. & Initial conditions & Remarks \\
\hline 1 & $J_{0}=0.0002$ & Fully coupled model \\
& $q_{0}=2.0\left(\mathrm{~m}^{2} / \mathrm{s}\right)$ & \\
\hline 2 & $h_{0}=1.4(\mathrm{~m})$ & Decoupled mode \\
\hline
\end{tabular}



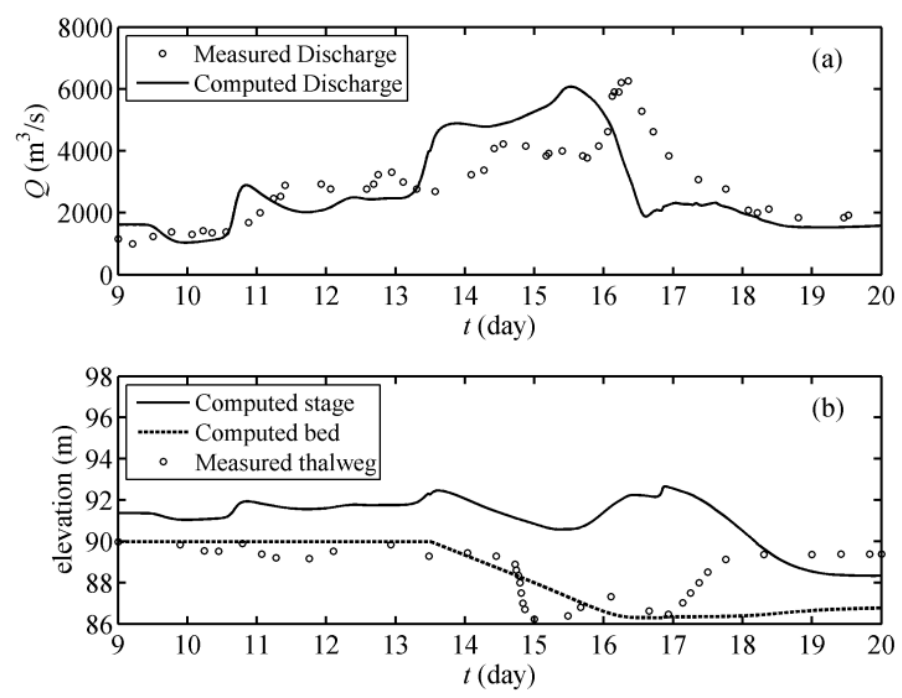

Figure 2. Computed results for case 1 at Huayuankou station in comparison with measured data.

The evolutional characteristics of hyperconcentrated floods are very complicated owing to its physical and propagation characteristics, and it is very difficult to explain it theoretically yet. When hyperconcentrated flood propagates through braided channel like the Yellow River and its tributaries on the Loess Plateau, extremely rapid fluvial process happens, in turn, the fluvial process also changes the propagation of flood waves and induces peculiar phenomena. From Figure 2(a), we can see that the measured peak discharge lagged behind the peak of computed hydrograph. This is owing to the flow storage and friction resistance by brained channel at the early stage of the flood, and it must be noted that the flood propagation speed is related to the channel configuration, channel shape changes from wide and shallow to narrow and deep during flood period, thus propagation speed changes.

The abnormal increase of the peak flow rate along the downstream course during the hyperconcentrated flood of "92.8" attracted much attention of Chinese hydraulic engineers and a lot of field investigations has been carried out to study the possible reasons [6] [7]. By Case 1, this phenomenon has numerically simulated by a fully coupled model (See Figure 2). Analyzing the bed elevation variation from numerical results and measured data at Huayuankou station, intensive erosion can be easily observed during late period of the flood. Scouring depth reached about $4 \mathrm{~m}$ (Figure 2(b)). This rapid fluvial process in turn changes the characteristics of the hyperconcentrated flow which exhibits "more incoming sediment and more delivered sediment". Thus large amount of sediment is entrained by the hyperconcentrated flood due to bed erosion, and this is the main reason for causing peak discharge increase along downstream course.

Figure 3 presents the computed results for Case 2 which uses a decoupled model with RHS of Equation (1) ignored in comparison with measured data at Huayuankou station. The flood peak is reduced along downstream course, and the abnormal phenomenon of downstream increase in peak discharge disappears. It indicates that the evolution process of hyperconcentrated flood including strongly interaction between the flow and bed evolution, therefore one has to simultaneously consider not only the flow and sediment transport, but also the morphological evolution, which is vital for processes with active sediment transport and morphological evolution like hyperconcentrated floods happened in Lower Yellow River. In the recent decades, decoupled models have also been developed for the numerical investigation of hyperconcentrated flood in the Lower Yellow River [15] [16]. However, according to the numerical results of Case 2, these models are, at least from theoretical perspective, not strictly correct, and may bring considerable errors.

\section{Conclusion}

The typical hyperconcentrated flood (“92.8”) occurred in the Lower Yellow River is studied with a series of numerical experiments. The abnormal downstream increase in peak discharge of hyperconcentrated flood in the Lower Yellow River is well simulated with a fully coupled model which incorporates the strong interaction between flood flow, active sediment transport and rapid morphological evolution. Numerical experiments indicate 

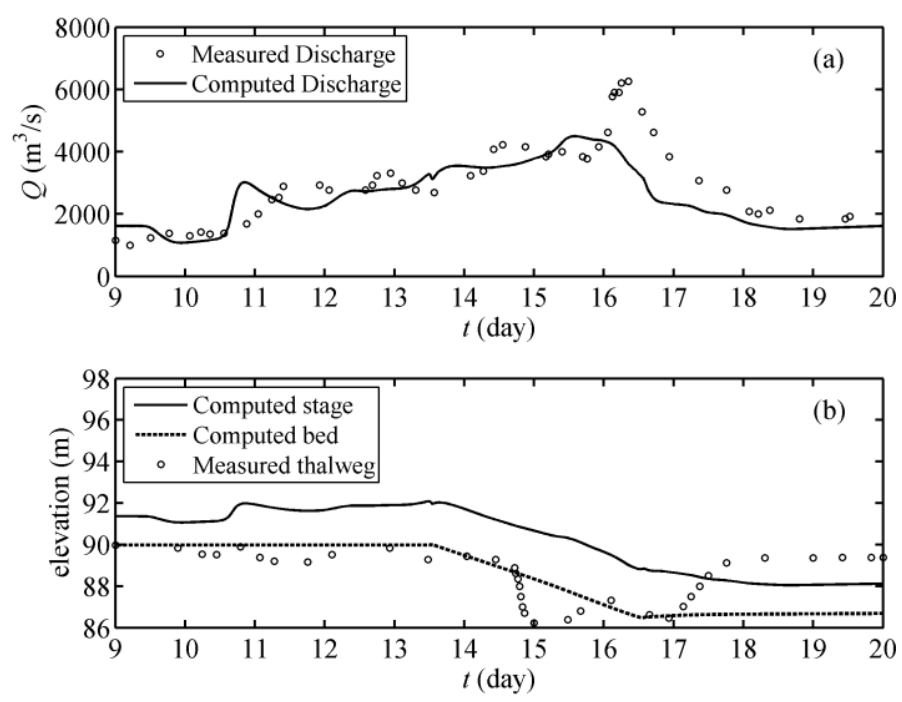

Figure 3. Computed results for case 2 at Huayuankou station in comparison with measured data.

that rapid fluvial evolution process happens during hyperconcentrated flood period, large amount of sediment is entrained by the hyperconcentrated flow due to bed erosion, and this is the main reason for causing peak discharge increase along downstream course.

\section{Acknowledgements}

The research is funded by Natural Science Foundation of China (Grants No. 51479009 and 51339001), and the special fund for basic scientific research business of central public research institutes (CKSF2016011/HL).

\section{References}

[1] Zhang, R. and Xie, J. (1993) Sedimentation Research in China: Systematic Selections. China Water and Power Press, Beijing.

[2] Chien, N., Wan, Z., Qian, N. and Quian, N. (1999) Mechanics of Sediment Transport. ASCE Press, Reston. http://dx.doi.org/10.1061/9780784404003

[3] van Maren, D., Winterwerp, J., Wu, B. and Zhou, J. (2009) Modelling Hyperconcentrated Flow in the Yellow River. Earth Surface Processes and Landforms, 34, 596-612. http://dx.doi.org/10.1002/esp.1760

[4] Xu, J.X. (1999) Erosion Caused by Hyperconcentrated Flow on the Loess Plateau of China. Catena, 36, 1-19. http://dx.doi.org/10.1016/S0341-8162(99)00009-0

[5] Wan, Z. and Wang, Z. (1994) Hyperconcentrated Flow. Balkema, Rotterdam.

[6] Qi, P. and Li, W.X. (1996) Evolutional Characteristics of Hyper-Concentrated Flow in Braided Channel of the Yellow River. International Journal of Sediment Research, 11, 9.

[7] Wang, Z., Qi, P. and Melching, C. (2009) Fluvial Hydraulics of Hyperconcentrated Floods in Chinese Rivers. Earth Surface Processes and Landforms, 34. http://dx.doi.org/10.1002/esp.1789

[8] Toro, E.F. (2001) Shock-Capturing Methods for Free-Surface Shallow Flows. Wiley, Chichester.

[9] Cao, Z.X., Pender, G. and Carling, P. (2006) Shallow Water Hydrodynamic Models for Hyperconcentrated SedimentLaden Floods over Erodible Bed. Advances in Water Resources, 29, 546-557. http://dx.doi.org/10.1016/j.advwatres.2005.06.011

[10] Shu, A. and Fei, X. (2008) Sediment Transport Capacity of Hyperconcentrated Flow. Science in China Series G: Physics Mechanics and Astronomy, 51, 961-975. http://dx.doi.org/10.1007/s11433-008-0108-4

[11] Winterwerp, J., Bakker, W., Mastbergen, D. and Van Rossum, H. (1992) Hyperconcentrated Sand-Water Mixture Flows over Erodible Bed. Journal of Hydraulic Engineering - New York, 118, 1508-1508. http://dx.doi.org/10.1061/(ASCE)0733-9429(1992)118:11(1508)

[12] Guo, J. (2002) Logarithmic matching and its applications in computational hydraulics and sediment transport Accordement logarithmique et applications en hydraulique numérique et en sédimentation. Journal of Hydraulic Research, 
40, 555. http://dx.doi.org/10.1080/00221680209499900

[13] Einstein, H. (1950) The Bed-Load Function for Sediment Transportation in Open Channel Flows. Water Resources Building, 43.

[14] Guo, J. and Julien, P. (2004) Efficient Algorithm for Computing Einstein Integrals. Journal of Hydraulic Engineering, 130, 1198. http://dx.doi.org/10.1061/(ASCE)0733-9429(2004)130:12(1198)

[15] Guo, Q.C., Hu, C.H., Takeuchi, K., Ishidaira, H., Cao, W.H. and Mao, J.X. (2008) Numerical Modeling of HyperConcentrated Sediment Transport in the Lower Yellow River. Journal of Hydraulic Research, 46, 659-667. http://dx.doi.org/10.3826/jhr.2008.3009

[16] Ni, J., Zhang, H., Xue, A., Wieprecht, S. and Borthwick, A. (2004) Modeling of Hyperconcentrated Sediment-Laden Floods in Lower Yellow River. Journal of Hydraulic Engineering, 130, 1025. http://dx.doi.org/10.1061/(ASCE)0733-9429(2004)130:10(1025) 